\title{
Treatment success of laser therapy for retinopathy of prematurity in referred and non-referred patients
}

\section{O sucesso do tratamento com terapia a laser para retinopatia da prematuridade em pacientes encaminhados e não encaminhados}

Caner Kara ${ }^{1}$, İkbal Seza Petriçli ${ }^{1}$, Emre Hekimoğlu ${ }^{1}$, Handan Akil $^{2}$, Özlem Beyazyildiz ${ }^{3}$

\section{ABSTRACT}

Purpose: Comparison of laser therapy (LT) outcomes in patients with retinopathy of prematurity (ROP) followed up in our clinic and referred from other centers. Methods: Medical records of 1,856 ROP patients were retrospectively evaluated, and a total of 128 patients who underwent LT were included in the study. The study population was divided into the following two groups: patients who were followed up and treated in our clinic (group 1, N=45) and patients who were referred to our clinic from other centers (group 2, $\mathrm{N}=83$ ). Data regarding birth weight, sex, gestational age, postnatal treatment time, disease localization, and stage were analyzed and compared between the two groups. Treatment success was defined by anatomic success 6 months after treatment.

Results: Patients in the referred group presented with a more advanced disease $(p<0.01)$, a lower treatment success rate $(p=0.01)$, and a longer time interval between diagnosis and $L T(p=0.04)$.

Conclusions: The treatment success rate of ROP was significantly lower in referred patients because of the potential delay in LT and more advanced disease at the time of treatment initiation.

Keywords: Early diagnosis; Laser coagulation; Retinopathy of prematurity/diagnosis; Treatment outcome

\section{RESUMO}

Objetivos: A comparação dos resultados da terapia a laser (LT) em pacientes com retinopatia da prematuridade (ROP) acompanhados em nossa clínicaeencaminhados por outras clínicas.

Método: Os arquivos de 1.856 pacientes com ROP foram analisados retrospectivamente eum total de 128 pacientes submetidos à LTforam incluídos no estudo. A população do estudo foi dividida em dois grupos; os pacientes que foram acompanhados e tratados em nossa clínica (grupo 1, $n=45$ ) e os pacientes que foram encaminhados à nossa clínica por outros centros (grupo 2, n=83). Os dados referentes a peso de nascimento, sexo, idade gestacional, tempo de tratamento pós-natal, localização e fase da doença foram analisados e comparados entre os grupos. O sucesso do tratamento foidefinido pelo sucesso anatômico no sexto mês após o tratamento.

Resultados: Pacientes no grupo de pacientes encaminhados apresentaram doença mais avançada $(p<0,01)$, taxa de sucesso inferior $(p=0,01)$ e maior intervalo de tempo entre o diagnóstico e tratamento a laser $(p=0,04)$.

Conclusões: A taxa de sucesso do tratamento da ROP é significativamente menor em pacientes encaminhados por causa de possivel atraso da LT e do estágio mais avançado da doença observado.

Descritores: Diagnóstico precoce; Fotocoagulação a laser; Retinopatia da prematuridade/diagnóstico; Resultado do tratamento

\section{INTRODUCTION}

The incidence of retinopathy of prematurity (ROP) has shown a marked increase due to increasing birth rates and advances within neonatal intensive care units (NICU) ${ }^{(1)}$. ROP-related vision loss, also called the "third epidemic," is more common in developed countries, and many of these countries are establishing screening programs for its management ${ }^{(1,2)}$.

Turkey, which ranks $90^{\text {th }}$ in the Human Development Index based on 2013 data, is one of the countries in this group ${ }^{(3)}$ and is also in the high-risk group for ROP-induced blindness ${ }^{(4)}$. To address this, the Turkish Ministry of Health has launched a new national program in 2011 for ROP and planned to establish diagnostic and treatment centers across the country ${ }^{(5)}$. Some of these centers are only intended as screening centers, whereas others are to offer both diagnostic and therapeutic services.

Individual countries should evaluate their screening and treatment programs at ROP diagnosis and treatment centers, serving as referral hospitals, by comparing treatment results from referred patients and non-referred patients.

In this study, we aimed to evaluate laser therapy (LT) outcomes in patients diagnosed and followed up in our clinic and referred from other centers during a three-year follow-up period.

\section{METHODS}

Medical records of 1,856 patients who were followed up in our clinic due to ROP between January 2011 and December 2013 were

\footnotetext{
Submitted for publication: September 17, 2015

Accepted for publication: December 3, 2015

Department of Ophthalmology, Etlik Zubeyde Hanim Women's Health Education and Research Hospital, Ankara, Turkey.

Department of Ophthalmology, Nevsehir State Hospital, Nevsehir, Turkey

${ }^{3}$ Department of Ophthalmology, Samsun Training and Research Hospital, Samsun, Turkey.
}

Funding: No specific financial support was available for this study.

Disclosure of potential conflicts of interest: None of the authors have any potential conflict of interest to disclose.

Corresponding author: Caner Kara. Etlik Zubeyde Hanim Women's Health Education and Research Hospital - Department of Ophthalmology - Yeni Etlik Caddesi, 55 - Keçiören, Ankara 06010 Turkey - E-mail: canerkara@hotmail.com

Approved by the following research ethics committee: Etlik Zubeyde Hanim Women's Diseases Teaching \& Research Hospital Institutional Review Board (\# 197). 
retrospectively evaluated. A total of 128 patients who underwent LT were included in the study, which was approved by the local Ethics Committee at Etlik Zübeyde Hanım Women Diseases Training and Research Hospital.

The study population comprised two groups: the first was made up by non-referred patients who were followed up and treated in our hospital (group 1, N=45), and the second group comprised patients who were referred from peripheral centers (group 2, N=83). Data regarding birth weight (BW), sex, gestational age (GA), and postnatal treatment period with disease localization and stage were retrospectively retrieved. Treatment results were evaluated in terms of anatomic success in the sixth post-treatment month according to the criteria of the Multicenter Trial of Cryotherapy of ROP (CRYO-ROP) study ${ }^{(6)}$ Although a normal view of the posterior fundus was considered to be an anatomic success, retinal detachment and macular folds were considered as anatomic failures.

Screening for ROP was performed for patients who were $<32$ weeks old and/or had a BW of $<1,500 \mathrm{~g}$ in the NICU department and for patients who were $>32$ weeks and/or had a BW of $\geq 1,500 \mathrm{~g}$, but with unstable clinical courses such as long-term oxygen therapy, sepsis, repeated blood transfusions, and long-term mechanical ventilation. The first examinations were performed on patients who were in their postnatal $4^{\text {th }}$ week; patients who were $<28$ weeks old were examined in the $30^{\text {th }}$ and $31^{\text {st }}$ weeks. Pupillary dilation prior to examination was enabled with 0.5\% tropicamide drops (Tropamide 0.5\%, Bilim, Turkey) and 2.5\% phenylephrine drops (Mydfirin 2.5\%, Alcon, USA) given 10 min apart (three times). After pupillary dilatation, binocular indirect ophthalmoscopic (Omega 2C, Heine, Germany) examination was performed using 20 and 28 D lenses with topical anesthesia obtained by instillation of $0.5 \%$ procaine hydrochloride (Alcain $0.5 \%$, Alcon, USA). A lid speculum and scleral indentator were used to visualize the peripheral retina. On each examination, the International Classification of ROP was used to denote the zone, stage, and extent of ROP, and whether "plus disease" or aggressive posterior (AP)-ROP was present in each eye $\mathrm{e}^{(7)}$. Patients with significantly increased arterial tortuosity and venous dilatation in at least four quadrants of zones 1 and 2 were classified as AP-ROP. Patients without ROP were examined by 2-week intervals until the vascularization had reached zone 3. Patients with ROP were examined weekly, and those who were candidates for AP-ROP were examined twice a week.

Treatments were performed according to the Early Treatment for Retinopathy of Prematurity trial recommendations (which encompass thresholds) as follows: (1) zone 1, any stage with plus disease; (2) zone 1 , stage 3, with or without plus disease; (3) zone 2, stage 2 or 3 with plus disease ${ }^{(8)}$. Upon informed consent, peripheral retinal ablation was performed by a 810-nm transpupillary diode laser (OcuLight ${ }^{\circledR}$ SL, Iridex, USA) on both eyes of patients for whom LT was indicated. Laser applications were carried out by a physician (EH) experienced in this field under remifentanil analgesia in the $\mathrm{NICU}^{(9)}$. Upon LT, topical steroids, antibiotics, and mydriatic therapy were administered to all patients. Follow-up care was conducted on postoperative day 1 and continued on a weekly basis until complete regression of ROP. Patients who did not show any improvement in extraretinal neovascularization and plus disease were re-evaluated for any skip area. Additional LT was carried out in the event of a skip area.

Statistical analysis was performed using SPSS v.21.0 for Windows. Continuous variables were presented as means \pm SD; categorical variables were indicated by numbers and percentages. The chi-square test and Fisher's exact test were used for categorical variables. Data were tested for normality using Kolmogorov-Smirnov and Shapiro-Wilk tests; between-group differences were analyzed using appropriate parametric (t-test) and non-parametric (Mann-Whitney U) tests. Probability $(p)$ values of $<0.05$ were considered statistically significant.

\section{RESULTS}

Laser therapy was applied to a total of 128 (6.9\%) of the 1,856 patients who were followed up at the eye clinic due to ROP. The number of patients by year was evaluated, and it was observed that the number of patients peaked in 2011. After that time, a reduction was observed in the number of patients (Table 1). The majority of the treatment population consisted of patients weighing $<1000 \mathrm{~g}$ and aged $<28$ weeks. The distribution of BW and GA of both groups is shown in table 2.

There was no statistically significant difference between the groups in terms of gender, GA, or BW ( $p>0.05)$. The postmenstrual age of preterm patients at the time of treatment was statistically higher in group 2 ( $p=0.04$, Mann-Whitney $U$ test). The distribution of the number of patients and demographic characteristics of both groups are shown in tables 1 and 2.

The overall anatomic success rate was $93.8 \%$. The anatomic success rate observed in groups 1 and 2 was 100\% and 90.4\%, respectively; the difference between the groups was statistically significant $(p=0.01)$. The groups were evaluated in terms of disease stage and location, and a statistically significant difference was found with regard to disease stage. Stage-3 disease was significantly more common in group 2, whereas stage-2 disease was significantly more common in group 1 $(p<0.01)$. There was no significant difference in terms of disease location between the two groups. Disease stage and location are shown in table 3.

\section{DISCUSSION}

In this study, we found that the treatment success rate for ROP was significantly reduced in referred patients, which may be due to a more

Table 1. Distribution of patients by year

\begin{tabular}{lccc}
\hline Years & $\begin{array}{c}\text { Non-referred patients } \\
\mathbf{n}(\%)\end{array}$ & $\begin{array}{c}\text { Referred patients } \\
\mathbf{n}(\%)\end{array}$ & Total \\
\hline 2010 & $5(71.4)$ & $2(28.6)$ & 7 \\
2011 & $23(34.8)$ & $43(65.2)$ & 66 \\
2012 & $12(33.3)$ & $24(66.7)$ & 36 \\
2013 & $5(26.3)$ & $14(73.7)$ & 19 \\
\hline Total & 45 & 83 & 128 \\
\hline N= number. & & &
\end{tabular}

Table 2. Demographic characteristics of referred and non-referred patients

\begin{tabular}{|c|c|c|c|c|}
\hline & & $\begin{array}{c}\text { Non-referred } \\
\text { patients }\end{array}$ & $\begin{array}{l}\text { Referred } \\
\text { patients }\end{array}$ & p value \\
\hline \multirow[t]{2}{*}{ Gender, n (\%) } & Male & $26(37.1)$ & $44(62.9)$ & $0.65^{*}$ \\
\hline & Female & $19(32.8)$ & $39(67.2)$ & \\
\hline \multirow[t]{2}{*}{ Gestational age $^{\dagger}$} & Mean $\pm S D$ & $27.2 \pm 2.4$ & $27.7 \pm 2.3$ & $0.22^{* *}$ \\
\hline & (Range) & $(24.00-33.00)$ & $(23.00-34.00)$ & \\
\hline \multirow[t]{2}{*}{ Birth weight (g) } & Mean $\pm S D$ & $963 \pm 221$ & $1021 \pm 299$ & $0.47^{* *}$ \\
\hline & (Range) & $(650-1600)$ & $(570-1850)$ & \\
\hline \multirow[t]{2}{*}{ Age at treatment ${ }^{\dagger}$} & Mean \pm SD & $36 \pm 4$ & $38 \pm 3$ & $0.02^{* *}$ \\
\hline & (Range) & $(32-46)$ & $(34.0-50.0)$ & \\
\hline Additional laser & N (\%) & $1(14.3)$ & $6(85.7)$ & $0.21^{* * *}$ \\
\hline \multirow{2}{*}{$\begin{array}{l}\text { Age at additional } \\
\text { laser treatment }^{\dagger}\end{array}$} & Mean $\pm S D$ & 41 & $41.2 \pm 5.3$ & $1.00^{* * *}$ \\
\hline & (Range) & - & $(37.1-49.7)$ & \\
\hline AP-ROP & $\mathrm{N}(\%)$ & $7(28)$ & $18(72.0)$ & $0.40^{*}$ \\
\hline Anatomic success & $N(\%)$ & $45(100)$ & $75(90.4)$ & $0.03^{*}$ \\
\hline
\end{tabular}

$\dagger=$ weeks; $\mathrm{SD}=$ standard deviation; $\mathrm{N}=$ number of patients; ${ }^{*}=$ Chi-square test; ${ }^{* *}=$ MannWhitney $U$ test; ${ }^{* * *}=$ Fisher's exact test; $\mathrm{AP}-\mathrm{ROP}=$ aggressive posterior ROP. 
Table 3. Disease stage and location of the groups

\begin{tabular}{|c|c|c|c|c|c|c|c|}
\hline & \multicolumn{3}{|c|}{$\begin{array}{c}\text { Non-referred patients } \\
n(\%)\end{array}$} & \multicolumn{3}{|c|}{$\begin{array}{l}\text { Referred patients } \\
\text { n (\%) }\end{array}$} & \multirow[b]{2}{*}{$p$ value } \\
\hline & Zone 1 & Zone 2 & Total & Zone 1 & Zone 2 & Total & \\
\hline \multirow[t]{2}{*}{ Stage 2} & 5 & 32 & 37 & 2 & 20 & 22 & $<0.01^{*}$ \\
\hline & (100) & (80) & $(82.2)$ & (16.7) & (29) & $(27.2)$ & \\
\hline \multirow[t]{2}{*}{ Stage 3} & 0 & 8 & 8 & 10 & 49 & 59 & $<0.01^{*}$ \\
\hline & (0) & (20) & $(17.8)$ & (83.3) & (71) & (72.8) & \\
\hline
\end{tabular}

$\mathrm{N}=$ number; ${ }^{*}=$ Chi-square test.

advanced disease in these patients and a delay in the initiation of LT. Here the anatomic success rate for referred patients was 93\%; however, the anatomic success rate for non-referred patients was $100 \%$. The overall anatomic success rate in our clinic was $96.1 \%$, and this rate is consistent with previous studies, which have reported success rates above $90 \%{ }^{(10-15)}$. Thus, we found a significantly better success rate in the non-referred group.

Laser photocoagulation is performed to destruct the non-vascularized retina, decreasing the release of angiogenic factors and subsequent neovascular complications ${ }^{(16,17)}$. Destruction of non-vascularized retina in the treatment of ROP was initially achieved with cryotherapy ${ }^{(6)}$. Later, LT proved as effective as cryotherapy in the treatment of ROP, inducing less pressure and trauma to the eye, being more effective for zone-1 and -2 diseases than cryotherapy using laser ${ }^{(17)}$.

Low BW and small GA are known to be risk factors for the development of ROP(18). Many previous studies included treatment groups mainly consisting of preterm patients weighing $<1000 \mathrm{~g}$ and aged $<28$ weeks ${ }^{(10,19-21)}$. In our study, consistent with previous reports, the average BW and GA in patients who received treatment were $900 \mathrm{~g}$ and 27 weeks, respectively; although these values were higher among referred patients, they were not statistically significant. Comparing patients with similar BW and GA, the apparent worst outcomes were observed in the group of referred patients. Differences in the treatment success rates between groups could be partially explained by the presence of advanced disease and late initiation of the treatment to the referred patients.

In this study, we showed that postnatal LT was initiated to the referred group only 2 weeks later than in the non-referred group. According to the ET-ROP and CRYO-ROP study results, the threshold ROP was set to nearly 37 weeks in patients with BWs $<1,251 \mathrm{~g}^{(8,22)}$. In several studies, patients were treated between 34 and 37 weeks, which may be the critical time interval for the progression of the ROP(23,24). After establishing a diagnosis of ROP and identifying an indication for treatment, treatment should be immediately initiated. The ET-ROP study emphasized that patients who require treatment should be treated within $48 \mathrm{~h}^{(8)}$. We found that treatment timing in the non-referred patient group was consistent with many previous studies and that treatment timing in the referred patient group was approximately 2 weeks later than the average of previous studies ${ }^{(23,24)}$. This situation may be a factor explaining the difference in success rate between the two groups. Treatment delay may have been caused by difficulties in terms of referring patients to experienced neonatal care units.

Another outstanding difference between the two groups was the presence of a significantly higher number of stage-3 ROP patients in the referred group. Our study showed that $71 \%$ of zone-2 patients also had findings of stage-3 ROP in the referred patient group. This proportion was found to be $29 \%$ in the non-referred patient group. Despite stage-2 patients having a treatment indication, many peripheral centers may not refer these patients until the development of stage-3 features, which may lead to lower success rates in the referred patient group. In a similar study, Nicoara et al. ${ }^{(25)}$ reported a higher incidence of zone-2 stage-3 patients in their referred patient group than in their local follow-up patient group. In their protocol, they closely observed stage-2 and zone-2 ROP with plus disease patients, and initiated prompt treatment if they reached stage 3 . However, referred zone- 1 and -2 patients were already at stage 3 on first examination because of delayed referral.

We evaluated the distribution of patients by year and found that the number of patients peaked in 2011, with a gradual reduction observed over the following years. This could be related to the establishment of the national screening program in 2011, which increased the awareness of ROP. After 2011, a decrease in the number of referred patients was seen in our study. We speculate that the decline is related to the establishment of peripheral treatment centers according to the national screening program. We also observed a decrease in the number of patients who sought treatment at our clinic. New regulations of oxygen protocols in the NICUs for preterm patients may be a cause of this decline, and this situation merits attention.

Our results showed that differences in the treatment success rates between the groups were caused by the presence of advanced disease and delayed treatment in referred patients. Nevertheless, for both groups, perinatal risk factors may affect the success of the treatment.

This study has some limitations: (1) the heterogeneous structure of the referred group, (2) the lack of comparisons of perinatal risk factors of the referred and non-referred patient groups, and (3) the fact that we evaluated and treated the patients ourselves; this situation may introduce bias. However, this issue could not be mitigated because of the retrospective structure of the study.

Early diagnosis and treatment of patients is the most important step to preventing ROP-induced blindness. Every country should have a policy aiming to improve neonatal care services, increase the number of the ROP screening-treatment centers, and decrease the referral rate with a view to decreasing ROP-induced blindness.

\section{REFERENCES}

1. Gilbert C, Rahi J, Eckstein M, O'Sullivan J, Foster A. Retinopathy of prematurity in middle-income countries. Lancet. 1997:350(9070):12-4

2. Gilbert C, Fielder A, Gordillo L, Quinn G, Semiglia R, Visintin P, et al. Characteristics of patients with severe retinopathy of prematurity in countries with low, moderate, and high levels of development: Implications for screening programs. Pediatrics. 2005; 115(5):518-25

3. United Nations Development Programme (UNDP). 2013 Human Development Report. [cited 2015 Jan 12]. Available from: http://hdr.Undp.Org/en/2013-report

4. Gilbert C. Changing challenges in the control of blindness in children. Eye (Lond). 2007;21(10):1338-43

5. Türkiye'de Özellikli Planlama Gerektiren Sağlık Hizmetleri 2011-2023 (Turkish). Turkish Ministry of Health, general directorate of curative services publications, Ankara, 2011. [cited 2015 Jan 12]. Available from: www.Tkhk.Gov.Tr/dosyalar/4adfd685cc544ff381e 2c31fc84a14a2.Pdf

6. Multicenter trial of cryotherapy for retinopathy of prematurity. Preliminary results. Cryotherapy for retinopathy of prematurity cooperative group. Arch Ophthalmol. 1988; 106(4):471-9.

7. International Committee of Classification of Retinopathy of Prematurity Revisited Arch Ophthalmol. 2005;123(7):991-9.

8. Early Treatment for Retinopathy of Prematurity Cooperative Group. Revised indications for the treatment of retinopathy of prematurity: Results of the early treatment for retinopathy of prematurity randomized trial. Arch Ophthalmol. 2003;121(12):1684-94.

9. Demirel N, Bas AY, Kavurt S, Celik IH, Yucel H, Turkbay D, et al. Remifentanil analgesia during laser treatment for retinopathy of prematurity: A practical approach in neonatal intensive care unit. Am J Perinatol. 2014:31(11):983-6.

10. Axer-Siegel R, Maharshak I, Snir M, Friling R, Ehrlich R, Sherf I, et al. Diode laser treat ment of retinopathy of prematurity: Anatomical and refractive outcomes. Retina. 2008;28(6):839-46

11. McLoone $\mathrm{E}, \mathrm{O}$ 'Keefe M, McLoone S, Lanigan B. Long term functional and structural ou tcomes of laser therapy for retinopathy of prematurity. Br J Ophthalmol. 2006;90(6): 754-9.

12. Kobylarz J, Piwowarczyk A, Romanowska-Dixon B. Diode laser photocoagulation for retinopathy of prematurity-outcomes in one-year observation. Klin Oczna. 2006; 108(1-3):36-8. Polish

13. Good WV, Carden SM. Retinopathy of prematurity. Br J Ophthalmol. 2006;90(3):254-5.

14. Essex RW, Carden SM, Elder JE. Two-year results of laser treatment for retinopathy of prematurity at a single neonatal intensive care unit. Clin Experiment Ophthalmol. 2005; 33(4):390-4 
15. Fallaha N, Lynn MJ, Aaberg TM, Jr., Lambert SR. Clinical outcome of confluent laser photoablation for retinopathy of prematurity. J AAPOS. 2002:6(2):81-5.

16. Soh Y, Fujino T, Hatsukawa Y. Progression and timing of treatment of zone i retinopathy of prematurity. Am J Ophthalmol. 2008;146(3):369-74.

17. O'Keefe M, Kirwan C. Screening for retinopathy of prematurity. Early Hum Dev. 2008 84(2):89-94

18. Avery GB, Glass P. Retinopathy of prematurity: Progress report. Pediatr Ann. 1988;17(8): 528-33.

19. Dhawan A, Dogra M, Vinekar A, Gupta A, Dutta S. Structural sequelae and refractive outcome after successful laser treatment for threshold retinopathy of prematurity. Pediatr Ophthalmol Strabismus. 2008;45(6):356-61.

20. Wani VB, Sabti KA, Kumar N, Raizada S, Kandari JA, Harbi MA, et al. Structural and func tional results of indirect diode laser treatment for retinopathy of prematurity from 1999 to 2003 in kuwait. Clin Ophthalmol. 2013;7:271-8.
21. Sahni J, Subhedar NV, Clark D. Treated threshold stage 3 versus spontaneously regres sed subthreshold stage 3 retinopathy of prematurity: A study of motility, refractive, and anatomical outcomes at 6 months and 36 months. Br J Ophthalmol. 2005;89(2): 154-9.

22. Palmer EA. Costenbader lecture. The factor of time in retinopathy of prematurity. J AAPOS. 2006;10(6):500-6.

23. Axer-Siegel R, Snir M, Cotlear D, Maayan A, Frilling R, Rosenbaltt I, et al. Diode laser treatment of posterior retinopathy of prematurity. Br J Ophthalmol. 2000;84(12):1383-6.

24. Kieselbach GF, Ramharter A, Baldissera I, Kralinger MT. Laser photocoagulation for retinopathy of prematurity: Structural and functional outcome. Acta Ophthalmol Scand. 2006;84(1):21-6

25. Nicoara SD, Cristian C, Irimescu I, Stefanut AC, Zaharie G. Diode laser photocoagulation for retinopathy of prematurity: Outcomes after 7 years of treatment. J Pediatr Ophthalmol Strabismus. 2014;51(1):39-45.

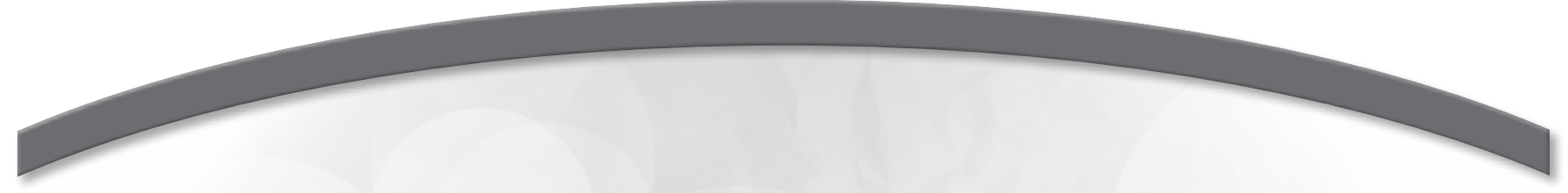

XIV Congresso Internacional de
Catarata e Cirurgia Refrativa

$X$ Congresso Internacional de Administração em Oftalmologia

III Congresso Internacional de
Enfermagem em Oftalmologia

\section{1 a 4 de junho de 2016}

Parque Anhembi

São Paulo - SP

Informações:

Site: www.brascrs2016.com.br 